\title{
Combined Microfiltration and Reverse Osmosis Process for Mining Water Treatment
}

\author{
Tomáš Bakalár ${ }^{1, *}$, Henrieta Pavolová ${ }^{1}$, Lubica Kozáková ${ }^{1}$, Petra Puškárová ${ }^{1}$, and Martina \\ Vasilková Kmecová ${ }^{1}$ \\ ${ }^{1}$ Technical University of Košice, Faculty of Mining, Ecology, Process Control and Geotechnologies, \\ Letná 9, 04200 Košice, Slovakia
}

\begin{abstract}
Nowadays mining water flowing out of an ore mine can be a serious threaten to the environmental due to high content of metals, especially heavy metals as well as solid particles. For this reason, this work proposes a membrane technology for mining water treatment so that the treated water meets the quality criteria of water for release into a recipient or industrial use. First polluted water was prepared, containing high concentrations of metals as well as other elements. Water was treated by selected membrane processes (stage 1 - microfiltration, stage 2- reverse osmosis). The stage 2 produced demineralized water, which was remineralised using Semidol - a dolomitic filter-material approved under DIN EN 1017 and DIN 2000. It can be concluded that the resulting water quality in terms of hardness and presence of nitrates and heavy metals improved and the water treatment method is suitable for preparation of both water safe for the environment and industrial water.
\end{abstract}

\section{Introduction}

Contaminated mining water is a serious problem worldwide nowadays. Treatment of water using membranes is common for many applications, including softening, desalination, TDS reduction and elimination of specific components such as iron, arsenic, and other metals and solid components $[1,2]$. Heavy metals are a serious problem for the environment that is why they should not be released from any technology, including mining and mine water [3] also after completed mining activity [4].

The ideal membrane has to meet the following criteria [5]:

a) the individual characteristics of the membrane such as pore size, pore size range, the number of pores per $\mathrm{cm}^{2}$, the proportion of the surface covered in pores, and many others should be adequately defined,

b) before and during the filtration the physical-chemical properties of the sample (i.e. the particle size distribution in water) may not be modified,

c) the chemical composition of the sample should not be influenced by organic or inorganic pollutants which are released from the membrane.

\footnotetext{
*Corresponding author: tomas.bakalar@tuke.sk
} 
Microfiltration (MF), in terms of membrane processes, is quite like classical filtration. The separation takes place based on the particle size $(0.1$ to $10 \mathrm{~mm})$ captured on the membrane. The pressure applied at microfiltration is relatively low $(<0.2 \mathrm{MPa})$ compared to other filtration processes [6]. It is often used as water pre-treatment for subsequent treatment by reverse osmosis or electrodialysis [7]. It is a reliable barrier method for disposing of solid microparticles, microorganisms and other pollutants in water from different sources. The use of membrane media ensures quality and reliable production of cleaned water, reducing downtime and maintenance costs. Membrane due to its fine porosity ensures high and consistent quality effluent water [6].

Reverse osmosis (RO) is a high-pressure method used for removal of dissolved metals and salts from the water. Due to typical pore size and large separation ability reverse osmosis is an effective way of removing almost all common water contaminants except volatile organic compounds [1].

It works on the same principle as microfiltration, ultrafiltration, and nanofiltration. It differs in membranes used and the working pressure. Particles of 0.1-1 nm in size are removed. Membranes only release solvent (water) and some soluble substances, including $(+\mathrm{I})$ and $(-\mathrm{I})$ ions $[8]$.

\section{Experimental}

Individual determinations of selected indicators that were conducted with a sample of water prepared in the laboratory are as follows:

- concentrations of calcium, magnesium, chloride, and sulphate by laboratory techniques,

- concentrations of nitrates ions by photometer (Palintest, UK),

- water reaction $(\mathrm{pH})$, temperature and conductivity (Hanna Combo, USA),

- heavy metal concentration - $\mathrm{As}, \mathrm{Cu}, \mathrm{Fe}, \mathrm{Ni}$ by Atomic Adsorption Spectrometer (iCE

3300 Thermo Scientific, USA)

Water samples analysis were done in the prepared sample and after each stage.

The water was treated by selected membrane processes (stage 1 - microfiltration and stage 2 - reverse osmosis). The output water after both the stages of treatment was (1) remineralised and (2) demineralised water (Fig. 1).

The microfiltration system is equipped with a ceramic membrane (Membralox). The active layer of the membrane is made of $\alpha-\mathrm{Al}_{2} \mathrm{O}_{3}$ which is placed on a rigid porous base. The membrane is resistant to mechanical stress, pressure shock, heat to $150{ }^{\circ} \mathrm{C}$. The $\mathrm{pH}$ range is from 0.5 to 13.5 which allows membrane cleaning by aggressive chemicals. Membrane has a tubular form with inner diameter of $7 \mathrm{~mm}$. Its length is $25 \mathrm{~cm}$ and the effective membrane area of is $50 \mathrm{~cm}^{2}$. The average pore size of the membrane is $0.1-0.5$ $\mu \mathrm{m}$.

The reverse osmosis system is also equipped with ceramic membrane. It is working in temperature range of $2-40{ }^{\circ} \mathrm{C}$ and pressure range $300-600 \mathrm{kPa}$.

Whereas the treated water is demineralised, an additional step, which enriches the demineralised water with minerals such as calcium and magnesium etc., is included after the reverse osmosis. In this system Semidol mineralizer is used.

Semidol is dolomitic filter material approved by DIN EN 1017 and DIN 2000 for treatment of drinking water, swimming pool water, industrial water, and for deacidification and removal of iron, manganese and silicates. It is a high-quality product made of pure dolomite. The content of pure $\mathrm{CaCO}_{3} \cdot \mathrm{MgO}$ is higher than $99 \%$; product is therefore of ideal stoichiometric composition. The content of accompanying inorganic substances is well below the permitted purity requirements specified in DIN and DIN EN. Semidol is therefore suitable as filter material; it is white because it is pure; the grains are homogeneous, porous with a rough surface without cracks. Semidol has a porosity of 
$14.4 \%$ and bulk density (depending on grain size) from 1.1 to $1.2 \mathrm{t}^{-3}$. It is available in the following particle sizes: 0: from 0.5 to $1.2 \mathrm{~mm}$, I: 0.5 to 2.5 millimetres, II: 2.0 to $4.5 \mathrm{~mm}$, and III 4.0 to $7.0 \mathrm{~mm}[9]$.

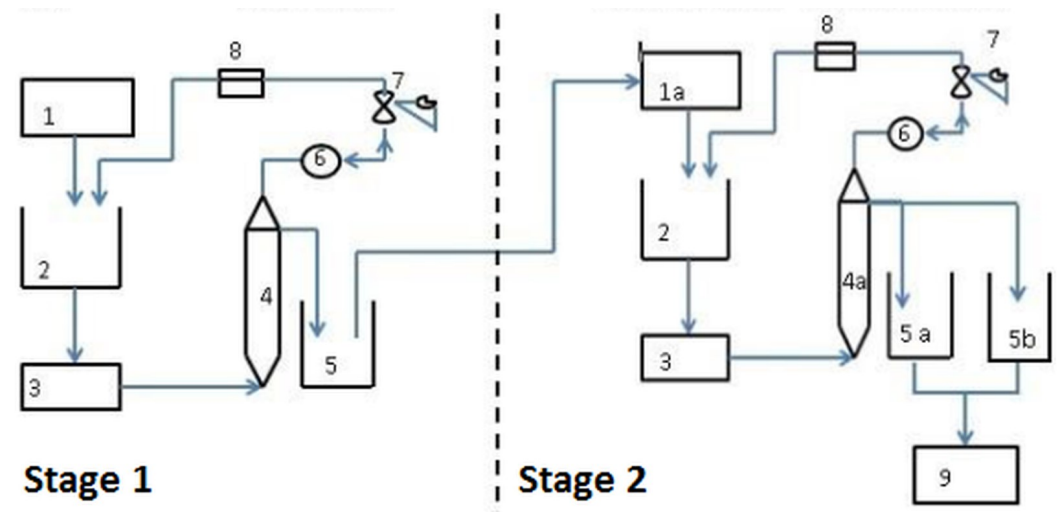

Fig. 1. Scheme of water treatment.

Key:

1 - analysis of original sample

1a - analysis of sample after microfiltration

2 - feed tank

3 - pump

4 - microfiltration membrane

$4 a-$ reverse osmosis membrane

\author{
5 - permeate \\ $5 \mathrm{a}-$ remineralised water \\ $5 \mathrm{~b}-$ demineralised water (after RO) \\ 6 - pressure sensor \\ 7 - valve \\ 8 - flow metre \\ 9 - analysis after treatment
}

\section{Results}

The results after each stage are shown in Figs. 2-4 and Table 1.

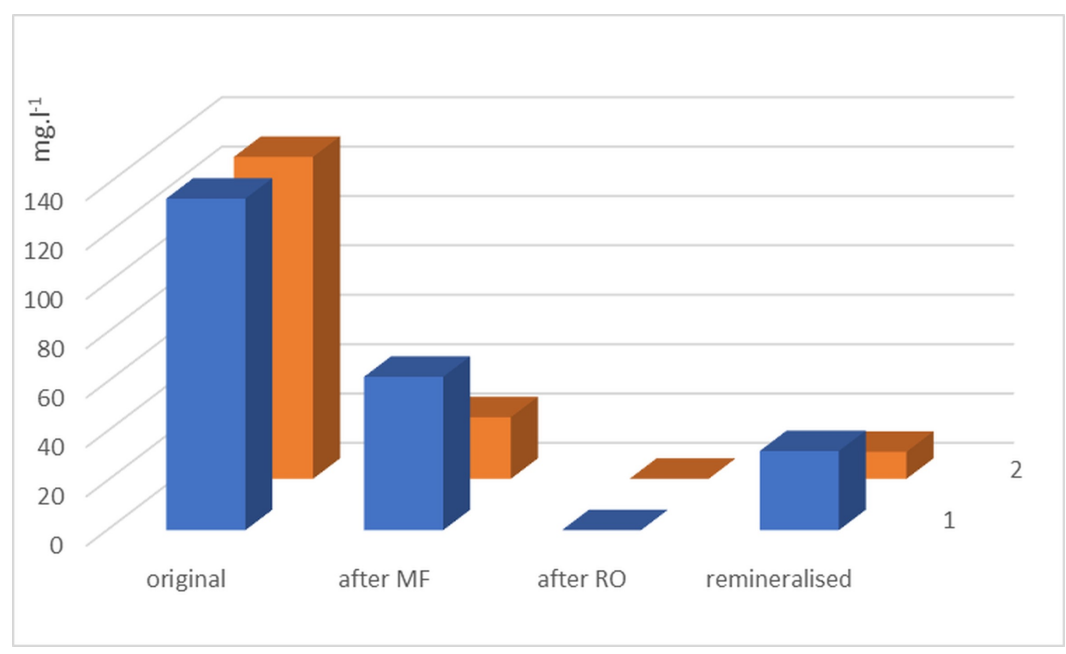

Fig. 2. Cations concentrations after each stage.
Key: $\quad 1-\mathrm{Ca}^{2+}$ ions
$2-\mathrm{Mg}^{2+}$ ions 
As shown in Figure 2, the original water sample before treatment contained 134.27, and $130.38 \mathrm{mg} . \mathrm{l}^{-1}$ of calcium, and manganese ions, respectively. After the treatment the value dropped to a concentration of 32.06 , and $10.94 \mathrm{mg} . \mathrm{l}^{-1}$, respectively.

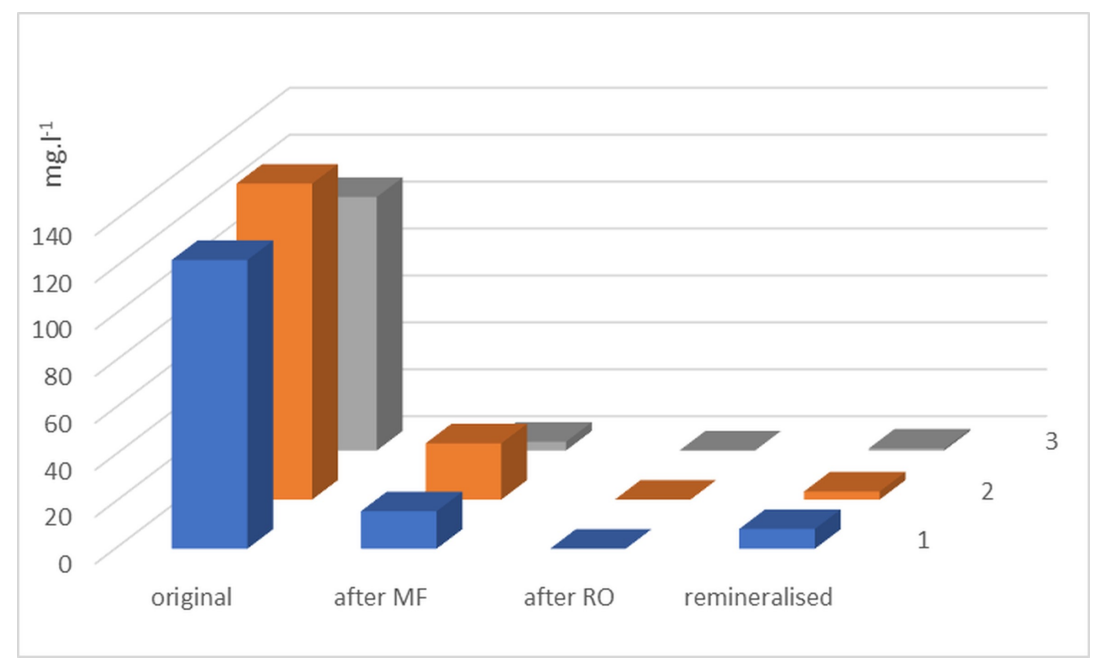

Fig. 3. Anions concentrations after each stage.

Key: $\quad 1-\mathrm{Cl}^{-}$ions

$$
2-\mathrm{SO}_{4}^{2-} \text { ions }
$$

$3-\mathrm{NO}_{3}{ }^{-}$ions

As shown in Figure 3, the original water sample before treatment contained 123.08, 134.69 , and $108.06 \mathrm{mg} .1^{-1}$ of chlorides, sulphates, and nitrate ions, respectively. After the treatment the value dropped to a concentration of $8.43,3.45$, and $0.84 \mathrm{mg} . \mathrm{l}^{-1}$, respectively.

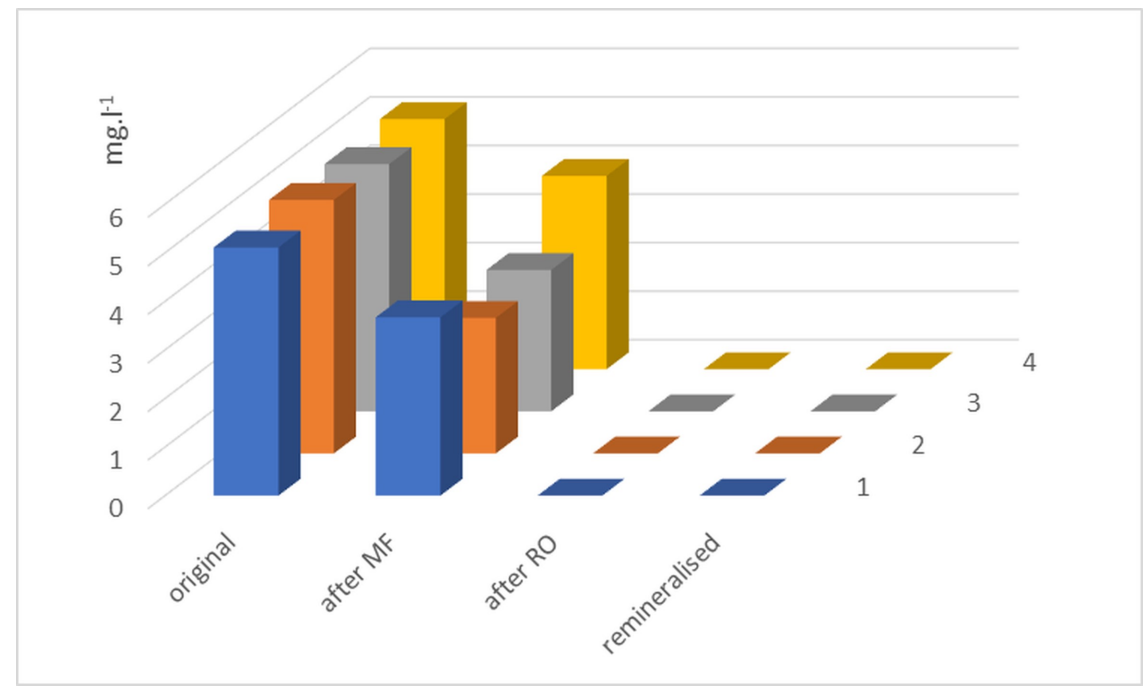

Fig. 3. Heavy metal ions concentrations after each stage.
Key: $\quad 1-\mathrm{As}^{5+}$ ions
$2-\mathrm{Cu}^{2+}$ ions
$3-\mathrm{Fe}^{3+}$ ions
$4-\mathrm{Ni}^{2+}$ ions

As shown in Figure 4, the original water sample before treatment contained about 5 mg..$^{-1}$ of arsenic, copper, iron, and nickel ions each. After the treatment the value dropped to zero. 
Table 1. Physical parameters after each stage.

\begin{tabular}{|c|c|c|c|}
\hline Stage & $\mathbf{p H}$ & $\begin{array}{c}\text { conductivity } \\
{[\mathbf{m S . m - 1 ]}}\end{array}$ & $\begin{array}{c}\text { Temperature } \\
{\left[{ }^{\circ} \mathbf{C}\right]}\end{array}$ \\
\hline Original & 7.18 & 693 & 10.5 \\
\hline After MF & 6.40 & 756 & 20.5 \\
\hline After RO & 7.59 & 0 & 19.7 \\
\hline Remineralised & 8.72 & 104 & 19.7 \\
\hline
\end{tabular}

Table 1 summarizes the changes of $\mathrm{pH}$, temperature and conductivity of the water in the original sample and after each stage. The water temperature after all the stages was influenced by the ambient temperature.

\section{Conclusion}

These days the protection of water and reduction of pollution is a very serious matter in national and international scale. There are many methods and technologies to reduce pollution. In this work the focus was put on an alternative technology of water purification consisting of reverse osmosis with microfiltration pre-treatment and re-mineralisation post treatment. This process effectively removes pollutants and water can be used in industrial technologies, released into the environment, or, after further appropriate treatment, even for drinking. The aim of this study was to design and implement water treatment by membrane technologies so that the treated water meets the quality criteria for water released into a recipient (watercourse) or for demineralised water. This technology is in accordance with the knowledge and requirements of sustainable development and appears as the most appropriate solution to achieve required quality of mining water after treatment. The use of treated water in technologies has also not only an ecological but also economic effects and mainly contributes to the "eco-image" of the company which decides for this method of processing and purification of mining water.

The quality of the water in terms of hardness presence of cations and anions, especially heavy metals, improved and therefore it can be confirmed that the used membrane technology is an effective method of water treatment.

\section{References}

1. L. H. Odel, Treatment Technologies for Groundwater (American Water Works Association, Denver, 2010)

2. M. Straka, S. Khouri, M. Paska, M. Busa, D. Puskas, Pol. J. Environ. Stud. 28, 3 (2019)

3. R. Rybar, M. Beer, D. Kudelas, B. Pandula, Metalurgija 55, 3 (2016)

4. M. Cehlar, J. Janocko, Z. Simkova, T. Pavlik, M. Tyulenev, S. Zhironkin, M. Gasanov, Resources Basel 8, 1 (2019)

5. J. Škvarla, Environmentálne častice (TU FBERG, Košice, 2013)

6. P. Kajitvichyanukul, N. K. Shammas, Y. Hung, L. K. Wang, J. Ananpattarachai, Membrane and Desalination Technologies (Springer, New York, 2011)

7. V. Bonnelye, L. Guey, J. Del Castillo, Desalination 222, 1-3 (2008)

8. J. Bindzar, Základy úpravy a čištění vod (VŠCHT, Prague, 2009)

9. Semidol. URL http://www.dolomitwerk.de/en/list-of-material/semidol/ 